\title{
PRODUÇÃO DE ZEÓLITAS A PARTIR DE CAULIM PARA ADSORÇÃO DE COBRE
}

\author{
E. C. RODRIGUES ${ }^{1}$, H. S. ALMEIDA ${ }^{2}$, J. C. F. REIS JR ${ }^{1}$, A. C. P. A. SANTOS ${ }^{1}$, P. R. O. \\ BRITO $^{1}$ e J. A. S. SOUZA ${ }^{1}$ \\ ${ }^{1}$ Universidade Federal do Pará, Programa de Pós-Graduação em Engenharia de Recursos \\ Naturais da Amazônia (PRODERNA/ITEC - UFPA). \\ ${ }^{2}$ Universidade Federal do Pará, Faculdade de Engenharia Sanitária e Ambiental (FAESA/ITEC \\ - UFPA). \\ E-mail para contato: ecr@ufpa.br
}

\begin{abstract}
RESUMO - O caulim é um material rico em silico-aluminatos e pode ser utilizado como matéria-prima para a produção de adsorventes denominados de zeólitas. O trabalho objetivou sintetizar a zeólita A em sistema agitado para adsorver cobre de uma solução de Sulfato de Cobre estabilizada com Hidróxido de Amônia. Os materiais de partida e de síntese das zeólitas foram caracterizados por Difração de Raios X e Microscopia Eletrônica de Varredura. Para a síntese do material zeolítico utilizou-se, como fonte de sílica e alumínio, o metacaulim, calcinado na temperatura de $600{ }^{\circ} \mathrm{C}$ por 2 horas em um forno cilíndrico e uma solução de $\mathrm{NaOH} 5 \mathrm{M}$. A síntese do material zeolítico ocorreu a $95^{\circ} \mathrm{C}$ em um reator composto por: balão volumétrico, manta aquecedora, agitador, controlador de temperatura e condensador. O processo de adsorção foi realizado em coluna de vidro com bomba de recirculação. Os resultados, obtidos por análise em ICP, comprovam a eficiência das zeólitas como adsorventes de metais pesados.
\end{abstract}

Palavras-chave: Caulim; Metacaulim; Zeólitas, remoção de cobre, adsorção.

\section{INTRODUÇÃO}

O objetivo do trabalho foi sintetizar a zeólita tipo A em sistema agitado para avaliar a capacidade de adsorção de cobre de uma solução de Sulfato de Cobre estabilizada com Hidróxido de Amônia. As zeólitas foram produzidas a partir de caulim calcinado em sistema agitado.

Segundo Santana et al. (2012), a Região Norte possui uma das maiores reservas brasileiras de Caulim, com destaque para as minas da região do Rio Capim, nordeste do estado do Pará, com duas minas em operação e a outra região a do Rio Jarí, com a mina localizada no Estado do Amapá com o processo de beneficiamento de caulim realizado no Estado do Pará. 
O processo de beneficiamento de caulim, assim como vários outros processos industriais, necessita de tratamentos físicos ou físico-químicos para a eliminação de impurezas, gerando com isso quantidade significativa de rejeito, muitas vezes exposto de forma inadequada ao meio ambiente. O rejeito do beneficiamento de Caulim, mesmo não sendo um produto tóxico, é objeto de discussões ambientais devido ao grande volume gerado, devendo ser dada uma destinação final adequada a esse tipo de resíduo (RODRIGUES, 2013).

Segundo Luz (1999), as Zeólitas são aluminosilicatos hidratados com uma estrutura cristalina de geometria precisa e poros de tamanho uniforme, formando canais de dimensões moleculares, com propriedades singulares de adsorção e troca iônica seletiva.

A zeólita A apresenta uma proporção Si/Al de 1:1, a mesma proporção é característica do caulim e do metacaulim, assim sendo sua fórmula oxida pode ser representada da seguinte maneira: $\mathrm{Na}_{2} \mathrm{O} \mathrm{Al}_{2} \mathrm{O}_{3} 2 \mathrm{SiO}_{2} 4,5 \mathrm{H}_{2} \mathrm{O}$.

A Zeólita A possui uma morfologia cúbica e geralmente é sintetizada na forma sódica. É conhecida por LTA, zeólita NaA e zeólita 4A (BRECK, 1973).

Com o propósito de encontrar uma solução para este resíduo é proposta a sua utilização na síntese de zeólitas, neste trabalho zeólita tipo A, a fim de utilizá-la como adsorvente de metais pesados. Ou seja, a utilização de um rejeito para compor um sistema de tratamento de águas residuárias.

\section{METODOLOGIA}

O procedimento de preparação da Zeólita a partir de rejeito de caulim consistiu, basicamente, em duas etapas apresentadas na Figura .

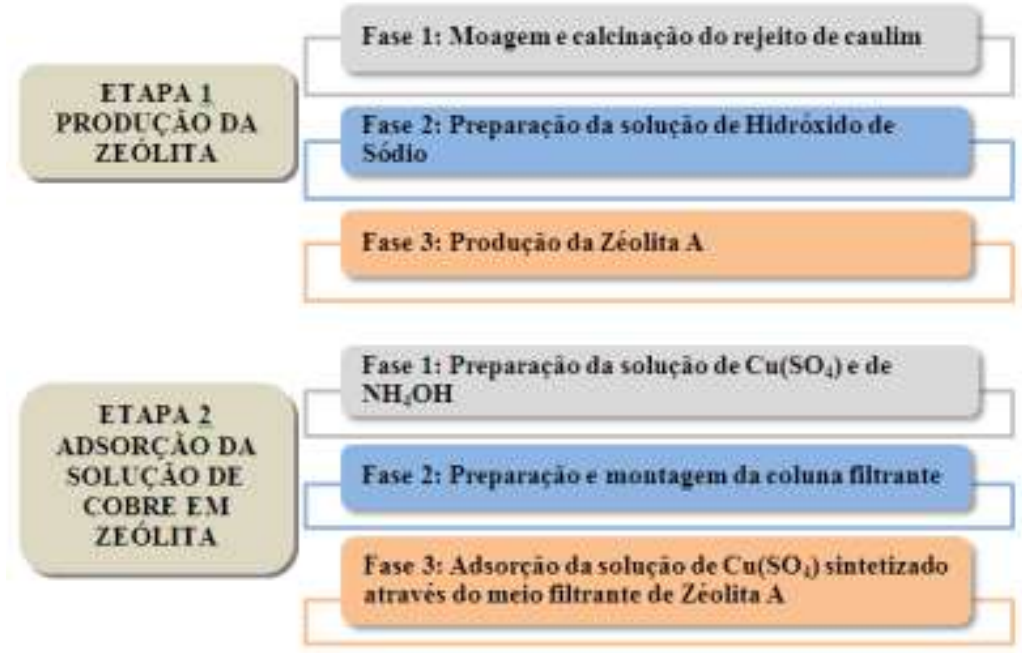

Figura 1 - Fluxograma simplificado das etapas da pesquisa. 


\subsection{Etapa 1 - Produção do material zeolítico}

A etapa de produção da Zeólita foi realizada em três fases: Moagem e calcinação do rejeito de caulim, preparação da solução de $\mathrm{NaOH}$ e preparação da Zeólita, conforme apresentado a seguir.

$\underline{\text { Fase 1- Moagem e calcinação do rejeito de caulim }}$

Nesta etapa, um determinado volume de rejeito de caulim foi introduzido em moinho de bolas durante um tempo médio de $20 \mathrm{~min}$, a fim de obter a granulometria ideal. Em seguida o rejeito moído, foi calcinado em um forno a uma temperatura de $600{ }^{\circ} \mathrm{C}$ durante $120 \mathrm{~min}$.

\section{Fase 2 - Preparação da solução de $\mathrm{NaOH}$}

\section{Fase 3 - Preparação da Zeólita}

Para a preparação da Zeólita foi realizada pesagem de $150 \mathrm{~g}$ de caulim calcinado, e aferido $700 \mathrm{~mL}$ de solução de $\mathrm{NaOH}$. Em seguida foi utilizado um agitador mecânico para a mistura dessas substâncias durante uma hora. A temperatura de agitação foi $95^{\circ} \mathrm{C}$.

Decorrido o tempo de agitação e mistura dos componentes citados, o produto desses foi transferido para um Becker para a realização da lavagem e estabilização do pH em neutro (sete). O procedimento de lavagem ocorreu por separação de fase pelo processo de sedimentação. Conforme a parte líquida era separada dos sedimentos, procedia-se com a troca do líquido até o alcance da faixa de $\mathrm{pH}$ desejado, próximo a neutralidade. Depois da fase de lavagem e estabilização de $\mathrm{pH}$, o produto obtido foi introduzido em estufa, para secagem durante 24 horas e então finalização da produção de Zeólita. As amostras foram caracterizadas por Difração de Raios X (DR X) e Microscopia Eletônica de Varredura (MEV).

\subsection{Etapa 2 - Adsorção da solução de Cobre}

A Etapa 2 foi realizada por meio da preparação da solução de $\mathrm{Cu}\left(\mathrm{SO}_{4}\right)$ e de $\mathrm{NH}_{4} \mathrm{OH}$, da montagem da coluna filtrante e da adsorção da solução de $\mathrm{Cu}\left(\mathrm{SO}_{4}\right)$ em meio filtrante (zeólitas sintetizadas), conforme apresentado a seguir.

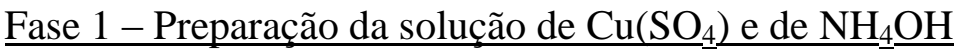

\section{Fase 2 - Montagem da coluna filtrante}

$\mathrm{Na}$ montagem da coluna filtrante foram utilizados materiais como coluna graduada, cap de $50 \mathrm{~mm}$ de esgoto, peneira, mangueiras de 5/16", T metálico e adaptadores como apresentado na Figura 2. 


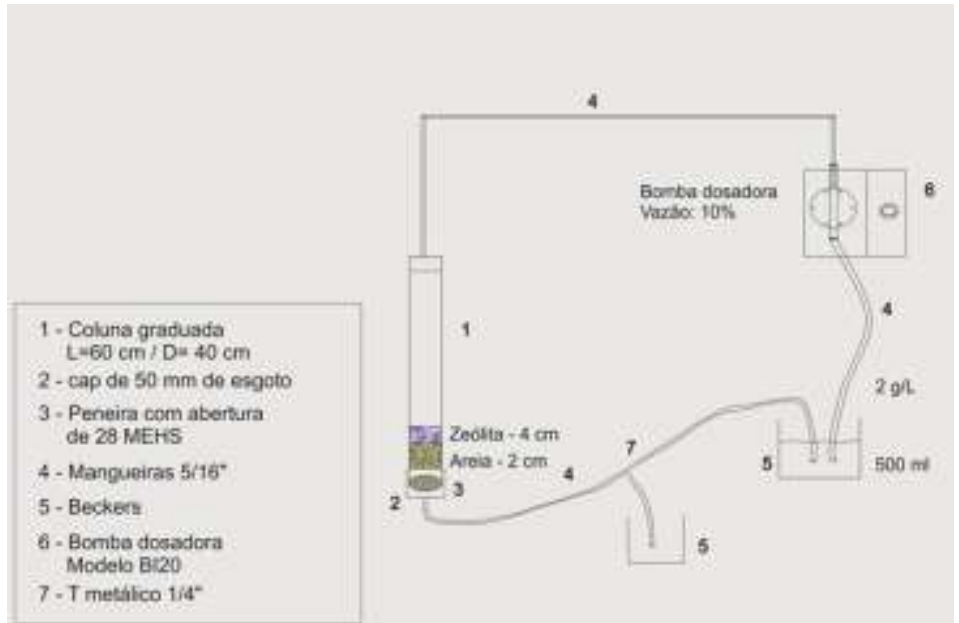

Figura 2 - Representação esquemática do sistema de adsorção.

Na Figura 3 são mostradas fotografias da montagem da coluna filtrante, com destaque para a peneira com abertura de 28 MESH utilizada no fundo da coluna.

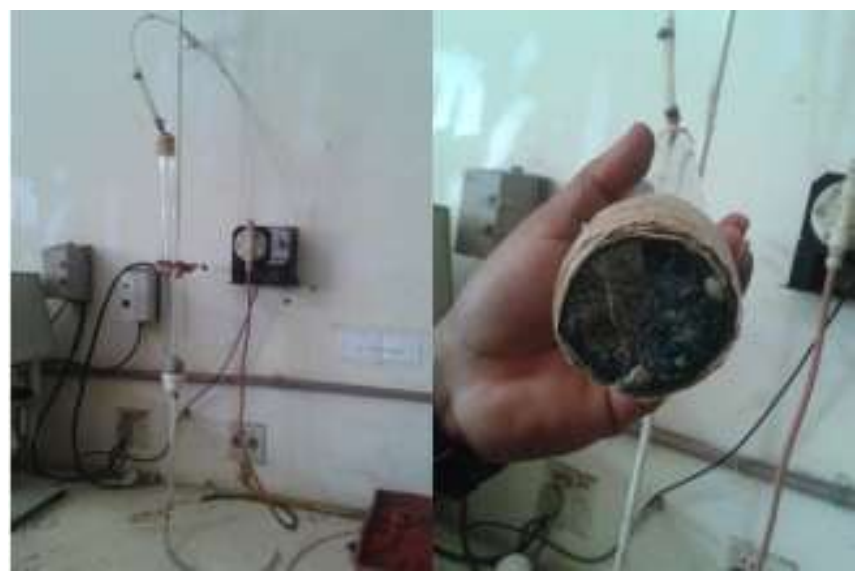

Figura 3 - Fotografias da Coluna de adsorção e da peneira utilizada como meio suporte.

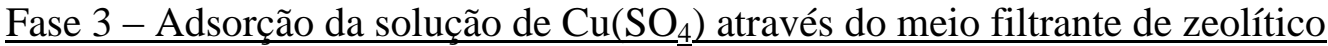

Para a definição dos procedimentos e relação de materiais a serem utilizados no processo de adsorção da solução de $\mathrm{Cu}(\mathrm{SO} 4)$ sintetizado, foram realizados dois testes preliminares para verificação do comportamento hidráulico e químico dos elementos envolvidos no processo, conforme descrito no Quadro 1. 
Quadro 1 - Testes preliminares das unidades do sistema de adsorção.

\begin{tabular}{|l|c|c|}
\hline Teste & Características & Observações \\
\hline 01 & $\begin{array}{c}\text { Bomba hidráulica operando } \\
\text { com 50\% de capacidade, } \\
\text { relação areia calcinada: } \\
\text { Zeólita de 6:4 (\%) }\end{array}$ & $\begin{array}{c}\text { Neste primeiro teste ocorreu o empacotamento das moléculas, tendo } \\
\text { como consequência o bloqueio da passagem de solução pela camada } \\
\text { filtrante, assim como elevado tempo de coleta das amostras iniciais. }\end{array}$ \\
\hline 02 & $\begin{array}{c}\text { Bomba hidráulica operando } \\
\text { com 10\% de capacidade, } \\
\text { relação areia calcinada: } \\
\text { Zeólita de 7:3 (\%) }\end{array}$ & $\begin{array}{c}\text { Neste segundo teste com a proporção de zeólita reduzida, o processo de } \\
\text { filtração ocorreu de forma gradual, porém lenta, o que possibilitou a } \\
\text { coleta de onze amostras do líquido filtrado, para posterior análise em } \\
\text { laboratório. }\end{array}$ \\
\hline
\end{tabular}

\subsection{Método de análise das amostras de $\mathrm{Cu}$}

O método utilizado para a leitura das amostras de cobre, foi o da cromatografia iônica, onde os constituintes iônicos são separados quando passam por uma coluna de troca iônica e a medida é realizada por detector adequado.

A cromatografia é um método físico-químico para separar misturas de substâncias. A separação é baseada na distribuição dos componentes entre duas fases: uma fase estacionária e uma fase móvel. A amostra contendo as substâncias é colocada na fase móvel e essas substâncias se moverão com maior ou menor rapidez, dependendo da sua afinidade com as duas fases.

O princípio do método é: uma quantidade relativamente pequena de amostra $(25 \mu \mathrm{L})$ é introduzida no cromatógrafo de íons. Os ânions de interesse são separados e medidos, usando um sistema composto de uma coluna cromatográfica supressora e um detector de condutividade.

As análises cromatográficas foram realizadas em um cromatógrafo modelo ICS-2000 (Dionex). O volume de injeção da amostra era de $25 \mu \mathrm{L}$, as colunas analíticas incluíam uma précoluna Dionex IonPac AG19 (2X50 mm) e uma coluna analítica Dionex ÍonPac AS19 (2x250 $\mathrm{mm}$ ). Detecção obtida por um detector de condutividade - célula DS3 Dionex com volume interno de $1,0 \mu \mathrm{L}$. A condutividade do eluente foi suprimida através do supressor aniônico CSRS300 2-mm) no modo de regeneração por autosupressão, aplicando-se uma corrente ao supressor de $72 \mathrm{~mA}$. A aquisição e tratamento de dados foi obtida através do software Chromeleon 7.0 (Dionex).

\section{RESULTADOS E DISCUSSÕES}

A Figura 4 apresenta o difratograma de Raios X do material zeolítico produzido com os picos característicos de zeólita tipo A bem definidos. Há também a presença do pico da zeólita sodalita. As fichas teóricas do Banco de Dados de ICDD (International Center for Diffraction Data) da ficha PDF 089-8015 provam que os picos principais da difração de raios $\mathrm{X}$ apresentados são da zeólita tipo NaA. 


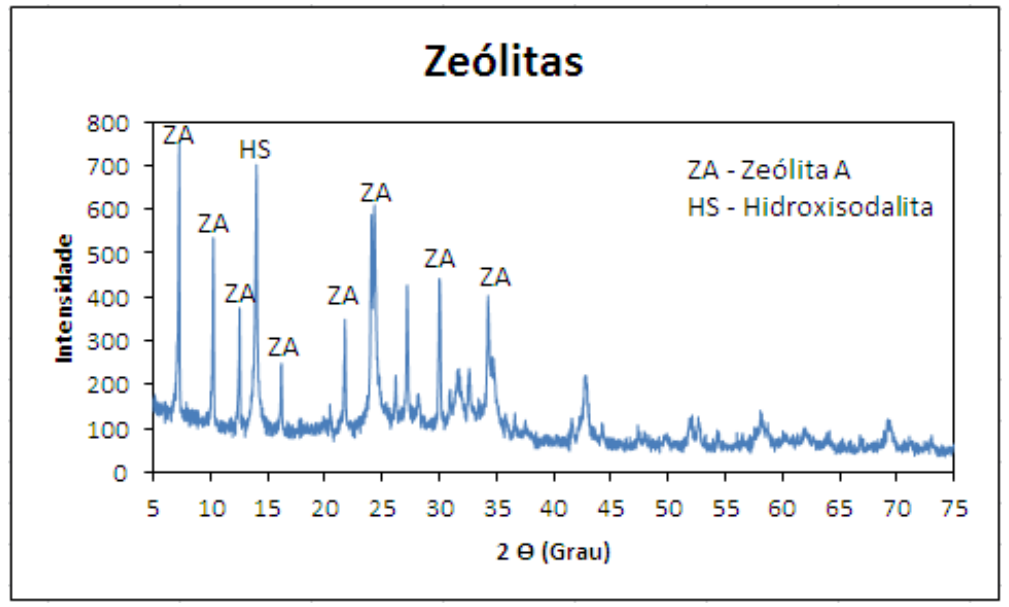

Figura 4 - Difratograma de Raios X do material zeolítico obtido.

A Figura 5 mostra a morfologia das zeólitas sintetizadas, os cristais cúbicos são característicos da zeólita A e a Hidroxisodalita possui morfologia esférica, assim como apresentado na imagem.

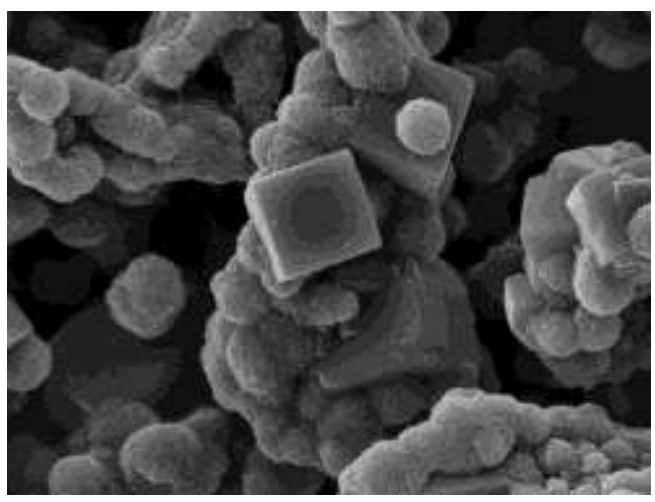

Figura 5 - Microscopia eletrônica de varredura do material zeolítico obtido.

Foram realizadas 11 coletas de amostras na coluna de adsorção, sendo uma a cada 30 min, o que possibilitou a análise da concentração de $\mathrm{Cu}\left(\mathrm{SO}_{4}\right)$ em cada ponto coletado, o que indica o grau de adsorção de $\mathrm{Cu}$ na amostra utilizada. A quantidade inicial de $\mathrm{Cu}$ foi de $2 \mathrm{~g} / \mathrm{L}$.

Na Tabela 1 são mostrados os resultados da estatística descritiva dos dados obtidos no experimento, ou seja, das concentrações de cobre nos 11 pontos amostrados e na Tabela 2 as taxas de remoção de cobre. 
Tabela 1 - Estatística descritiva dos dados obtidos no experimento.

\begin{tabular}{lr}
\hline Estatística Descritiva & Valor \\
\hline Mínimo & 0,46 \\
Máximo & 1,08 \\
Amplitude Total & 0,62 \\
Mediana & 0,51 \\
Primeiro Quartil (25\%) & 0,48 \\
Terceiro Quartil (75\%) & 0,56 \\
Média & 0,57 \\
Desvio Padrão & 0,18 \\
\hline
\end{tabular}

Tabela 2 - Taxas de remoção de $\mathrm{Cu}$ em $\mathrm{mg} / \mathrm{L}$ para solução de $2 \mathrm{~g} / \mathrm{L}$ de $\mathrm{Cu}_{2} \mathrm{SO}_{4}$.

\begin{tabular}{ccc}
\hline Amostra & $\begin{array}{c}\text { Concentração } \\
\text { de Cu ma/L }\end{array}$ & $\begin{array}{c}\text { Remoção } \\
\text { \% }\end{array}$ \\
1 & 1,08 & 99,95 \\
2 & 0,58 & 99,97 \\
3 & 0,46 & 99,98 \\
4 & 0,47 & 99,98 \\
5 & 0,47 & 99,98 \\
6 & 0,49 & 99,98 \\
7 & 0,49 & 99,98 \\
8 & 0,51 & 99,97 \\
9 & 0,51 & 99,97 \\
10 & 0,67 & 99,97 \\
11 & 0,54 & 99,97 \\
& Média & 99,97 \\
\hline
\end{tabular}

De acordo com a análise descritiva dos dados de concentração de $\mathrm{Cu}$, a média observada foi de 0,57 , com desvio padrão de 0,18 unidades para mais e para menos. A concentração máxima observada no experimento foi de $1,08 \mathrm{mg} / \mathrm{L}$ e a mínima de $0,46 \mathrm{mg} / \mathrm{L}$, o que resultou numa amplitude total de 0,62. É importante ressaltar que o primeiro valor observado, que foi a máxima concentração obtida, resultou, possivelmente, do arraste de zeólita através da peneira suporte da coluna, fato que foi verificado visualmente no primeiro frasco de coleta.

Dos valores de concentração de $\mathrm{Cu}, 50 \%$ estão abaixo de 0,51 (mediana), e $25 \%$ das observações estavam abaixo de 0,48 unidades ( $1^{\circ}$ Quartil) e $75 \%$ estavam acima de $0,56\left(3^{\circ}\right.$ Quartil).

No que se refere a capacidade de adsorção, verificou-se que o experimento resultou em taxas de remoção de $\mathrm{Cu}$, superiores a $99 \%$, sendo a média de 99,97\%, o que corrobora para a eficiência da zeólita A na remoção de cobre.

\section{CONCLUSÕES}

O caulim mostrou-se como excelente matéria-prima na síntese de zeólitas, o que pode ser comprovado pelas técnicas de caracterização (DRX e MEV).

As taxas de remoção de cobre obtidas foram superiores a $99 \%$, o que comprova a capacidade de remoção do metal presente em uma solução, tal característica sugere a possível utilização deste material em sistemas de tratamento de efluentes líquidos onde se visa à remoção de metais pesados. 
O processo de adsorção de cobre apresentou resultados satisfatórios, uma vez que, o material zeolítico não estava pelotizado e por isso houve empacotamento durante a realização do ensaio de adsorção.

\section{REFERÊNCIAS}

BRECK, D. W.Zeolitic Molecular Sieves: structure, chemistry and use. Wiley, N. Y., (ed.), 1974 .

CORREA, Edinelson Saldanha. Síntese e caracterização de analcina obtida a partir o rejeito caulim com aplicação em adsorção. Universidade Federal do Pará. Instituto de Tecnologia (Dissertação de Mestrado). Belém, 2006.

LUZ, A. B. Zéolitas: Propriedades e usos industriais. Rio de Janeiro: CETEM/cnpq, 1995.

RODRIGUES E. C. 2013. Influência do Tempo de Ração e da Concentração de Sódio na Sóntese de Zeólitas. Dissertação de Mestrado, Instituto Tecnológico, Faculdade de Engenharia Química, Universidade Federal do Pará, 2013.

SANTANA, D. L.; SARAIVA, A. C. F.; NEVES, C. F.; Silva, D. L. Zeólita A sintetizada a partir de rejeitos do processo de beneficiamento de caulim. Cerâmica, 2012. 238-243. 